\title{
Compliance with the mass chemotherapy program for lymphatic filariasis
}

\author{
K T A A Kasturiratne ${ }^{1}$, B A H R Premaratne ${ }^{2}$, A Pathmeswaran', N R de Silva'and H J de Silva
}

(Index words: Diethylcarbamazine, drug delivery, publicity material, adverse effects of drug)

\begin{abstract}
Objective To evaluate compliance with the single dose mass chemotherapy program for control of filariasis, and to determine factors influencing compliance in the Gampaha district.
\end{abstract}

Design A prospective study employing a pre-tested selfadministered questionnaire.

Methods Four groups comprising individuals over one year old with residence in the Gampaha district for over one year were surveyed. Data collection was started two weeks after the mass chemotherapy program.

Results 2300 questionnaires were distributed, 1983(86.2\%) were returned, and $1935(84.1 \%)$ were sufficiently complete for analysis ( 857 males; mean age 39 years, $S D=19.5$ ). Over $96 \%$ had heard of filariasis and the mass chemotheraphy program, but only $60.3 \%$ of those over 11 years of age were aware of asymptomatic carriage of the parasite. $1289(66.6 \%)$ out of the total sample surveyed (1935 individuals) had obtained the diethylcarbamazine tablets, and $1221(63.1 \%)$ had taken the drug. Of the possible demographic factors that could have influenced compliance only educational level seemed to play an independent significant role, compliance being lowest at both extremes of educational level. The main problem with compliance was obtaining the drug from distribution centres.

Conclusions Compliance with the mass chemotherapy program to control filariasis needs improvement. Strategies should include a better system for distributing the drug, and altering the content of the publicity material used by the program to target less compliant groups, and improve aspects of knowledge regarding filariasis that seem inadequate at present.

\section{Introduction}

Lymphatic filariasis is endemic in Sri Lanka. It is a major cause world-wide of clinical morbidity influencing socio-economic development and the world's second leading cause of permanent and long term disability. In 1997, the World Health Organizaton and its member states recognised lymphatic filariasis (LF) as a major problem, and made a commitment to eliminate it world-wide (1). Mass chemotheraphy has been identified as one of the two main general control strategies (2). Repeated annual or semiannual distribution of a single dose of diethylcarbamazine (DEC) significantly reduces microfilaraemia leading to interruption of transmission of the parasite by mosquitoes
$(2,3)$. It has few side-effects and a low cost of delivery, and is therefore suitable for a country such as Sri Lanka. However, the cost effectiveness of such a program is dependent on the rate of compliance of the target population (4).

A single dose mass chemotherapy program is presently being conducted in the filariasis endemic regions in Sri Lanka. Under this program all individuals living in the targeted regions over one year old, excluding pregnant women, are expected to take a single dose of DEC (300 mg for adults; $150 \mathrm{ml}$ for children) every six months. They are expected to collect tablets from the centres of distribution conducted by the Medical Officer of Health of the area. In 2001 , the single dose chemotheraphy program took place on the $18^{\text {th }}$ and $19^{\text {th }}$ of May, and was continued during the National Health week that followed.

The aim of this study was to evaluate compliance with the semi-annual single dose mass chemotherapy program among some population groups in the Gampaha district, and to determine demographic and other factors influencing compliance.

\section{Methods}

The Gampaha district has a population of $2064651(5)$. The study population consisted of individuals over one year old with a period of residence in the Gampaha district of over one year. We studied four groups within this population. These included consecutive outpatients attending a medical clinic conducted by the Professorial Medical Unit, Colombo North Teaching Hospital, Ragama, consecutive patients who sought treatment at a private medical consultation centre in Nittambuwa in the Attanagalla Divisional Secretarial Division and their family members, residents in randomly selected households in two Grama Sevaka divisions (Kendaliyaddapaluwa-West in the Mahara Divisional Secretarial Division, and Galudupita in the Wattala Divisional Secretarial Division) in the Gampaha district.

A sample of nurses and medical officers working at the Colombo North Teaching Hospital, Ragama, who were resident in the district for over one year, was also studied as a key group, but were not included in the detailed analysis.

Data collection was started two weeks after the National Health Week during which the chemotherapy program took place, and completed in three weeks, using a pre-tested self-administered questionnaire. The questionnaire was pretested on 100 persons attending an outpatient clinic in the Colombo North Teaching Hospital. Part 1 of the questionnaire tested the participants' knowledge

Lecturer, and Senior Lecturer, Department of Community and Family Medicine, 'Lecturer, Department of Medicine, ^Associate Professor, Department of Parasitology, and ^Professor, Department of Medicine; Faculty of Medicine, University of Kelaniya. (Accepted 22 October 2001. Corresponding author KTAAK, Fax +94 1 958337). 
on filariasis, the possibility of asymptomatic carriage of microfilarial worms, and the single dose chemotherapy program in operation. If they were aware of the program their information source was assessed. To exclude age bias only individuals above 11 years of age were selected when analysing Part 1. Part 2 of the questionnaire tested whether the participants obtained and used the drug, reasons for not obtaining or using the drug, whether side-effects were experienced and what they were, and whether they had taken anti-filarial treatment earlier. All questionnaires returned by the study population were included in this analysis. Data was analysed using Epi Info (Version 6) and SPSS.10, using the statistical tests chi squared and multiple logistic regression.

\section{Results}

2300 questionnaires were distributed, 1983 (86.2\%) were returned, and 1935 (84.1\%) were sufficiently complete for analysis. The distribution of the population sample is given in Table 1. There were 857 males in the study population. The age distribution was 1 to 92 years $($ mean $=39$, $\mathrm{SD}=19.5$ ). Residential areas of those attending medical clinics included all the Divisional Secretarial Divisions of the Gampaha district. The majority were from Attanagalla (43\%), Gampaha (14\%) and Ja-ela (13.7\%); the smallest group was from Divulapitiya $(0.2 \%)$. The "key group" comprised 69 nurses and 73 doctors.

$1859(96.1 \%)$ of the sample surveyed had heard of filariasis. Of the $76(3.9 \%)$ who had not, $56(73.7 \%)$ were below 11 years of age. Among those over 11 years of age, $1065(60.3 \%)$ were aware of asymptomatic carriage of the parasite. This awareness was not significantly associated with gender. Multiple logistic regression analysis showed that both the level of education and monthly family income were independently associated with this awareness. The level of education had a direct positive association with awareness, but the association between awareness and the monthly family income was not linear (Table 2). $1723(97.5 \%)$ of those over 11 years of age were aware of the control program; the two most common sources of information were the media (34\%) and the Medical Officer of Health and his staff (26.2\%). Neighbours and friends (6.7\%) and hospitals $(6.9 \%)$ played a secondary role.

$1289(66.6 \%)$ out of 1935 individuals had obtained the DEC tablets and $1221(63.1 \%)$ had taken the drug, i.e. $94.7 \%$ of those obtaining the drug had used it. Compliance was similar in the four categories within the study sample (Table $1)$. The frequency of obtaining and using the drug respectively in the key group of doctors $(35.6 \%, 31.5 \%)$ and nurses $(60.8 \%, 59.4 \%)$ was less than that of the study population. In the study population, gender was not significantly associated with obtaining the drug $(\mathrm{OR}=1.16 ; 95 \%$ $\mathrm{CI}=0.99-1.12$ ), but the level of education was. Individuals in the middle strata of education (passed grade 5, passed grade 8 and passed GCE O/L) were more likely to obtain the drug than others. Those who had higher education were the least likely to obtain the drug compared to all others. Those who had no formal education or had obtained an education below grade 5 had more likelihood of obtaining the drug than those who had passed GCE A/L or who had higher education. Those who had the lowest education were most likely to have used the drug once it was obtained. The likelihood of using the drug was similar in the three sub-groups in the middle strata of education. Those with the highest level of education had the least likelihood of using the drug. Monthly family income was not significantly associated with obtaining and using the drug when the level of education was accounted for. When the relationship between awareness of asymptomatic carriage and obtaining the drug was assessed, 761(71.4\%) of the 1065 who were aware of this fact obtained the drug compared to $421(60 \%)$ of the 702 who were unaware of the fact $\left(\mathrm{k}^{*} \mathrm{~s} 2 \mathrm{~S} .2 ; \mathrm{p}<0 . \mathrm{OOl}\right)$.

The commonest $[\mathrm{n}=356(50.3 \%)]$ reason given for not obtaining or using the drug was inability to obtain it from the centres. Fear of interaction with current medication [n=99 $(14 \%)]$, forgetting to use the drug after obtaining it $[\mathrm{n}=72(10.2 \%)]$, considering it as unnecessary $[\mathrm{n}=59(8.3 \%)]$, and fear of adverse effects $[n=47(6.6 \%)]$ were the other common reasons. $94(8.1 \%)$ of the 1165 who responded to the relevant question started that they had experienced adverse effects to DEC. The commonest was giddiness $(69.6 \%)$, followed by nausea or vomiting (12\%), urticaria $(4.3 \%)$ and abdominal pain $(3.3 \%)$.

$1219(63.1 \%)$ of the sample surveyed had taken antifilariasis treatment previously. Of these, 933 (76.5\%) had also used the drug during the present mass chemotherapy program. Of the 716 who had not taken DEC previously only $288(40.2 \%)$ had taken the drug during the program (OR 4.8,95\% CI 3.9-5.9). The source of previous treatment was the Medical Officer of Health $(85.8 \%)$, government hospitals $(9.5 \%)$ and general practitioners $(3.5 \%)$.

\section{Table 1. Distribution of the sample and compliance in obtaining and using the drug}

\begin{tabular}{|c|c|c|c|}
\hline Category & Number(\%) & $\begin{array}{l}\text { Compliance } \\
\text { Obtained } \\
\text { the drug }\end{array}$ & $\begin{array}{l}(\%) \\
\text { Used } \\
\text { the drug }\end{array}$ \\
\hline Outpatients - Medical clinic & $531(27.5)$ & $349(65.7)$ & $323(60.8)$ \\
\hline Outpatients - Consultation centre & $608(31.4)$ & $411(67.6)$ & $396(65.1)$ \\
\hline Community - Galudupita & $325(16.8)$ & $219(67.4)$ & $215(66.2)$ \\
\hline Community - Kendaliyaddapaluwa & $471(24.3)$ & $310(65.8)$ & $287(60.9)$ \\
\hline Total & $1935(100)$ & $1289(66.6)$ & $1221(63.1)$ \\
\hline
\end{tabular}


Table 2. Factors affecting compliance with the mass chemotherapy program

Factor

\section{Gender}

Male

Female

\section{Total Number \\ (those>llyears)}

$857(770)$

1078 (997)

Education

No formal education/ < Grade 5307 (178)

Passed Grade S 198 (166)

Passed Grade 8

Passed G. C. E. O/L 548 (548)

Passed G. C. E. A/L 290 (289)

Obtained higher education 119 (119)

Monthly family income

$\begin{array}{lr}<\text { Rs. } 2500 & 630(569) \\ \text { Rs. } 2500-4999 & 656(597) \\ \text { Rs. } 5000-7999 & 335(306) \\ \text { Rs. } 8000-12000 & 131(124) \\ >\text { Rs. } 12000 & 183(171)\end{array}$

\section{Awareness of
filariasis* \\ (given as \%)}

98.7

99

96.6
96.9
98.5
99.6
100
100

$\begin{array}{ll}\begin{array}{l}\text { Awareness of } \\ \text { the control }\end{array} & \begin{array}{l}\text { Awareness of } \\ \text { asymptomatic } \\ \text { program* }\end{array} \\ \text { (given as \%) } & \begin{array}{l}\text { carriage* } \\ \text { (given as } \%)\end{array}\end{array}$

97

94.4
94.6
97.4
98.2
99.3
99.2

97.7
99.2
99.3
100
100

\section{6}

59.3

$\begin{array}{ll} & \text { OR } 95 \% C l \\ 39,9 & \mathrm{RG}^{* *} \\ 47.1 & 1.3(0.9-2.1) \\ 54.6 & 1.8(1.3-2.6) \\ 62 & 2.4(1.7-3.5) \\ 75 & 3.9(2.5-6.0) \\ 87.4 & 8.0(4.1-15.5)\end{array}$

Obtained the drug (given as \%)

$$
64.8
$$

$\begin{array}{lll} & \text { OR } & 95 \% C 1 \\ 62.9 & 1.1 & (0.7-1.8) \\ 69.7 & 1.6 & (1.0-2.5) \\ 71.5 & 1.7 & (1.1-2.6) \\ 68.4 & 1.5 & (1.0-2.2) \\ 60.0 & 1.0 & (0.7-1.6) \\ 59.7 & R G \#\end{array}$

OR $95 \% C I$

$\begin{array}{ll}52.7 & R G * * \\ 54.4 & 0.8(0.6-1.0) \\ 69.9 & 1.3(0.9-1.7) \\ 75.1 & 1.4(0.9-2.3) \\ 77.7 & 1.4(0.9-2.2)\end{array}$

Used the drug (given as \%)

61.5

64.4

-Individuals $>11$ years of age only; RG - Reference group; Multiple Logistic Regression *• Model $\mathrm{k}^{\prime}=133.3 ; d f=9 ; p<0.001$

\# $\quad$ Model $\mathrm{k}^{*}=16.8 ; d f=5 ; \mathrm{p}=0.005$

$+\quad$ Model $\mathrm{k}^{\prime}=15.6 ; d f=5 ; \mathrm{p}=0.008$ 


\section{Discussion}

For an elimination campaign employing mass chemotherapy to be successful, a high treatment coverage (generally accepted as over $80 \%$ of individuals in a community) is considered desirable $(3,4)$, although SO to $80 \%$ is considered a realistic coverage. Our study shows an overall coverage of $63.1 \%$. Recent independent evaluations in India, another country with a high disease burden due to filariasis, has also shown that it is difficult to achieve coverage rates of more than $60 \%(3,4)$.

Nearly all the individuals in our survey had heard of filariasis and the mass chemotherapy program. However, only about $60 \%$ were aware of asymptomatic parasitaemia. This may have had a bearing on compliance, as compliance was better in persons with this knowledge. The main problem with compliance seemed to be obtaining the drug from the distribution centres. Almost all of those who obtained DEC used it. Among those who used the drug, reported adverse effects were uncommon and not serious, confirming the safety and tolerability of the drug.

Of the possible demographic factors that could have influenced compliance only educational level seemed to play an independent significant role. Compliance was lowest at both extremes of educational level, and highest among those who had passed grade 3 , grade 8 and GCE O/L. Possible explanations for this may be scepticism and indifference among the better educated with regard to mass programs delivering free medication, and ignorance of the benefits of such medication among the least educated. Further evidence in support of this interpretation is the even lower compliance to the program among doctors and nurses. Compliance was high among those who had taken anti-filariasis treatment previously.

To improve compliance and make future programs more cost effective, new strategies should be developed, including a better system for distributing the drug (eg. house- to-house delivery), and altering the content of the publicity material used by the program to target the less compliant groups in the community and to improve aspects of knowledge regarding filtriasis that seem inadequate at present.

References

1. Anon. Lymphatic filariasis. WHO Weekly Epidemiological Record (No.20) 2001; 76: 149-56.

2. Molyneux DH, Neira M, Liese B, Heymann D. Lymphatic filariasis: setting the scene for elimination.7ra/ittJcfion.s of the Royal Society of Tropical Medicine and Hygiene 2000; 94: 589-91.

3. Das PK, Ramaiah KD, Vanamail P, Pani SP, Yuvaraj J, Balarajan K, Bundy DAP. Placebo-controlled community trial of four cycles of single-dose diethylcarbamazine or ivermectin against Wuchereria bancrofti infection and transmission in India. Transactions of the Royal Society of Tropical Medicine and Hygiene 2001; 95: 336-41.

4. Ramaiah KD, Das PK, Appavoo NC, Ramu K, Augustin DJ, Vijay Kumar KN, Chandrakala AV. A program to eliminate lymphatic filariasis in Tamil Nadu state, India: compliance with annual single-dose DEC mass treatment and some related operational aspects. Tropical Medicine and International Health 2000; 5: 842-7.

5. Census of Population and Housing 2001: Population by Province, District and D.S. Division (Provisional). Department of Census and Statistics, Ministry of Finance and Planning Government of Sri Lanka, 2001.

6. Anon. Advocacy for elimination filariasis. WHO/ TDER News, Oct. 2000: No 63, 6.

7. Plaisier AP, Stolk WA, van Oortmarssen GJ, Habbema JDF. Effectiveness of annual ivermectin treatment for Wuchereria bancrofti infection. Parasitology Today 2000; 16: 298-302.

\section{The exercise of clinical autonomy}

In the exercise of their clinical autonomy, doctors are not at liberty to prescribe expensive medicines that afford no added therapeutic benefit over and above cheaper alternatives. When resources are limited, cost-effectiveness must be taken into account because the moneys used to pay for medicines belong to us all. To prescribe or consume resources in ways that are inefficient is to waste taxpayers' money and represents a betrayal of the community's trust. (J C Mucklow. How can we afford costly medicines? Journal of the Royal College of Physicians of London 2000; 34: 124-7) 